\title{
Aportes teórico-conceituais de Valério Cruz Brittos à Economia Política da Comunicação
}

Theorical-conceptual contributions of Valério Cruz Brittos to the Political Economy of Communication

\author{
César Ricardo Siqueira Bolaño* \\ Anderson David Gomes dos Santos ${ }^{* *}$
}

\section{RESUMO}

Este texto discute o desenvolvimento de conceitos ligados à Economia Política da Comunicação (EPC) a partir da produção acadêmica de Valério Cruz Brittos de 2001 a 2012, em especial seus aportes para os conceitos de: (a) barreiras à entrada nos mercados comunicacionais e a especificação da noção de padrão tecnoestético; (b) "fase da multiplicidade da oferta" para a periodização do mercado brasileiro de televisão; e (c) "PluriTV", para a caracterização do atual ambiente de disseminação das telas. Trata-se de explicitar a sua inserção na trajetória da EPC brasileira como contribuição para o seu ulterior desenvolvimento.

Palavras-chave: Conceitos; Valério Cruz Brittos; Economia Política da Comunicação.

\begin{abstract}
This paper discusses the development of concepts linked to the Political Economy of Communication (PEC) from the academic production of Valério Cruz Brittos between 2001 and 2012, specially his contribution to the concepts of: (a) barriers to entry in the communication markets and the specification of the notion of techno-aesthetic patterns; (b) "offer multiplicity phase" in the periodization of the Brazilian television market; and (c) "Pluri-TV”, to characterize the current environment for the dissemination of screens. It is about making explicit its insertion in the trajectory of the Brazilian EPC as a contribution to its further development.
\end{abstract}

Keywords: Concepts; Valério Cruz Brittos; Political Economy of Information; Communication and Culture.

\section{INTRODUÇÃO}

Valério Cruz Brittos foi uma das grandes referências da Economia Política da Comunicação (EPC) na primeira década do século XXI, com artigos publicados nas principais revistas do campo da Comunicação. Foi editor da Revista EPTIC, presidente do capítulo brasileiro da União Latina de Economia Política da Informação, da Comunicação e da Cultura (ULEPICC-Brasil) - com papel de destaque na criação da Unión Latina de Economía Política de la Información, Comunicación y Cultura (ULEPICC),

\footnotetext{
* Doutor em Ciência Econômica pela Universidade Estadual de Campinas. Professor Titular da Universidade Federal de Sergipe (UFS). Endereço: Universidade Federal de Sergipe - Cidade Universitária Prof. José Aloísio de Campos. Jardim Rosa Elze. São Cristóvão-SE. CEP: 49100-000. E mail: bolano.ufs@gmail.com.

** Mestre em Ciências da Comunicação pela Universidade do Vale do Rio dos Sinos (Unisinos). Campus Sertão da Universidade Federal de Alagoas (UFAL), Santana do Ipanema-AL. Endereço profissional: Rua Prefeito Adeildo Nepomuceno Marques, n. 472, Monumento, Santana do Ipanema-AL. CEP: 57500-000. E-mail: andderson.santos@gmail.com.
} 
em 2002, da qual foi vice-presidente, de 2008 a 2010 - e um dos pesquisadores da Comunicação mais destacados do período, com produção acadêmica importante especialmente para os estudos sobre televisão. ${ }^{1}$

O objetivo deste texto é retomar aspectos centrais da produção teórica de Brittos, falecido em 2012, indicando possíveis caminhos para considerá-los no estudo da nova estrutura dos sistemas de mediação, contribuição perfeitamente válida e importante para a compreensão de fenômenos atuais. Com isso, pretende-se contribuir para a preservação da influência da escola brasileira, suas categorias e sua genealogia na unificação do campo da EPC em nível internacional, em operação desde 1992.

Restringimos o nosso período de análise ao intervalo 2001-2012, utilizando como metodologia a revisão de literatura, começando pela tese de Brittos (2001) e seguindo para livros, capítulos de livros e artigos, alguns deles com orientandos. 0 recorte deixa de lado a importante produção anterior do autor, seguindo o paradigma dos chamados Estudos Culturais (EC) latino-americanos, mais por limitação de espaço, pois considera-se a importância também daquela contribuição (interna) aos EC, pelas suas especificidades e pela possibilidade que abre para o diálogo (externo) interdisciplinar com a EPC.

Assim, trataremos basicamente da contribuição de Brittos para a especificação dos conceitos: de padrão tecno-estético e de barreiras à entrada nos mercados comunicacionais; de "fase da multiplicidade da oferta" na periodização do mercado brasileiro de televisão; e de PluriTV para a caracterização do atual ambiente de disseminação das telas nos mais variados ambientes. Centramos a nossa atenção, em temas relacionados ao estudo dos mercados da comunicação, com destaque para a análise microeconômica, que constitui parte importante da contribuição da EPC brasileira, explicitando a consistência do paradigma a que Brittos se filia.

\section{Breve nota biográfica}

Valério Cruz Brittos nasceu em Pelotas-RS em 1964, onde concluiu quase que simultaneamente os cursos de graduação em Direito, na Universidade Federal de Pelotas (1986), e em Jornalismo, na Universidade Católica de Pelotas (1987). Em 1996, concluiu a dissertação de Mestrado "Recepção e TV a cabo: a mediação da identidade cultural pelotense", no Programa de Pós-Graduação em Comunicação na Pontifícia Universidade Católica de Porto Alegre, na perspectiva dos Estudos Culturais latinoamericanos, mas apresentando já um diferencial em relação à maioria dos Estudos de Recepção, dadas as especificidades do incipiente mercado de TV a cabo brasileiro, que exigia inovações metodológicas para o seu estudo. Na versão publicada em livro, em 2002, a influência da EPC já aparecia, indicando a mudança de perspectiva que já se anunciava.

De 1991 a 1995, foi professor da Universidade Católica de Pelotas e em 1996 entrou para os quadros da Universidade do Vale do Rio dos Sinos (Unisinos), onde viria a realizar a parte mais significativa da sua contribuição à EPC, inclusive a criação do grupo Comunicação, Economia Política e Sociedade (Cepos), em 2001, que viria a somar-se ao Observatório de Economia e Comunicação da Universidade Federal de

\footnotetext{
${ }^{1}$ Brittos foi, por exemplo, o segundo autor mais referenciado nos primeiros 15 anos de publicação da Revista EPTIC (de 1999 a 2014), a principal do campo da EPC no âmbito ibero-americano (LOPES; SANTOS; MOTA, 2015).
} 
Sergipe (OBSCOM), coordenado por César Bolaño, e à Rede de Economia Política das Tecnologias da Informação e da Comunicação (EPTIC), que publicava a Revista EPTIC desde 1999, da qual Brittos seria o editor de 2006 até o seu falecimento. Com a constituição do grupo Cepos e a sua inserção no Programa de Pós-Graduação em Ciências da Comunicação da Unisinos, orientando trabalhos de graduação, mestrado e doutorado, por sua parte, ficava estabelecido o eixo São Leopoldo-São Cristóvão, em torno do qual se consolidou a EPC brasileira nos anos 2000.

É a conclusão do doutorado em 2001, com a tese "Capitalismo contemporâneo, mercado brasileiro de televisão por assinatura e expansão transnacional", no Programa de Pós-Graduação em Comunicação e Cultura da Universidade Federal da Bahia (UFBA), e o seu retorno à Unisinos que garantirão a sua inserção no campo da Comunicação como principal liderança acadêmica da EPC brasileira, ao assumir não apenas a edição da Revista EPTIC, mas também a coordenação do Grupo de Trabalho de Economia Política da Compós (Associação Nacional dos Programas de PósGraduações em Comunicação) e, a partir de 2010, o Grupo de Pesquisa na Intercom (Sociedade Brasileira de Estudos Interdisciplinares da Comunicação).

A tese, dividida em 6 capítulos ("Comunicação e espaço econômico"; "Mídia e concorrência"; "Capitalismo e mudança"; "TV paga e desenvolvimento"; "Televisão brasileira e evolução"; e "Globo, transnacionalização e Portugal"), segue a linha inaugurada por Bolaño (1988), no estudo do mercado brasileiro de televisão, adaptada ao estudo da TV paga. Em ambos os casos, trata-se de estudar o processo de oligopolização e a dinâmica de construção e ruptura de barreiras à entrada.

O trabalho de Brittos avança não apenas na construção do conceito de barreiras à entrada no campo comunicacional, mas também na caracterização da própria TV de massa no Brasil, ao definir a ideia de uma "fase da multiplicidade da oferta", como complemento à periodização proposta no conhecido trabalho de Sérgio Mattos (2010). O pesquisador alia ainda na sua tese uma discussão sobre a internacionalização da Rede Globo, estudando especialmente o caso da sua expansão em Portugal.

Em levantamento realizado a partir do Google Acadêmico $^{2}$, a tese foi citada em outros 42 trabalhos científicos disponíveis de forma digital. Dois livros coorganizados em parceria com César Bolaño, que também têm como objeto de estudo a televisão no Brasil, possuem ainda mais referências: "A TV brasileira na era digital: exclusão, esfera pública e movimentos estruturantes" (BOLAÑO, BRITTOS, 2007), citado 184 vezes; e "Rede Globo: 40 anos de poder e hegemonia" (BRITTOS, BOLAÑO, 2005), com 176 citações.

O grupo de pesquisa Cepos, que ele fundou, se especializara em estudar os processos audiovisuais num momento de reconfiguração tecnológica e, consequentemente, de mercado, cujos impactos ainda vivemos. Com o seu falecimento, o grupo acabou transferindo-se para a Universidade Federal de Sergipe, sob a liderança de César Bolaño, fundindo-se ao OBSCOM, que trata hoje de preservar a sua memória, divulgando e desenvolvendo a herança que ele nos deixou. Este artigo é uma pequena contribuição nesse sentido.

2 Busca realizada partir do nome do autor, com recorte de 2001 a 2020, realizado em: <https://scholar.google.com/>. Acesso em: 15 maio 2020. 


\section{PADRÕES TECNO-ESTÉTICOS E AS BARREIRAS À ENTRADA NA PRODUÇÃO DE BENS SIMBÓLICOS}

A proposição e o desenvolvimento de conceitos ligados aos estudos do mercado de produção audiovisual, seja pela TV aberta, paga ou pela internet, são a marca principal da trajetória de Brittos.

Possas (1987) indica que para garantir a estabilidade dos oligopólios por parte das empresas dominantes, barreiras à entrada devem ser constituídas, tanto em relação à concorrência potencial como à efetiva, neste último caso, defendendo as partes de mercado fidelizadas pela líder. Bolaño (2000) aplicou o conceito ao caso das indústrias culturais, especialmente o audiovisual, desenvolvendo o de padrão tecnoestético como uma espécie de barreira à entrada característica desse tipo de indústria. ${ }^{3}$

Brittos adota o conceito de barreiras à entrada na sua tese para o estudo do mercado de TV paga e o desenvolve posteriormente, produzindo, com base na literatura microeconômica e nos estudos sobre os mercados da comunicação, uma classificação das barreiras adotadas em setores produtores de bens simbólicos. Em artigo teórico que trata especificamente do conceito, afirma que:

Em torno das barreiras desenvolvem-se não só as estratégias das empresas líderes, para mantê-las, mas de outros agentes, efetivos ou potenciais, que querem derrubá-las e erguer outras em seu lugar. Por elas, as empresas acumulam potencial de mercado capaz de alavancar operações que conduzem a uma ampliação de sua dimensão (BRITTOS, 2005, p. 77).

Na sua tese, considerando as singularidades da produção de bens culturais, divide as barreiras nos mercados televisivos em estético-produtivas e político-institucionais, referidas a determinantes ligadas, respectivamente, à produção - como o padrão tecno-estético que Bolaño (2000, p. 234) define, em trecho citado por Brittos, como "uma configuração de técnicas, de formas estéticas, de estratégias, de determinações estruturais, que definem as normas de produção cultural historicamente determinadas de uma empresa ou de um produtor cultural" - e à regulamentação, como é, por exemplo, a distribuição de frequências. A liderança do mercado poderia ser verificada, do ponto de vista quantitativo, tanto pelos "números de audiência, assinantes e pagantes em geral, embora também possam ser atestadas via medidas que envolvam entradas de recursos, como receita e lucro líquidos" (BRITTOS, 2005, p. 81).

No caso da TV, é na produção dos programas que se situam os maiores esforços econômicos, demarcando a capacidade de acesso a recursos financeiros como vantagem competitiva fundamental, ainda que o elemento preponderante para se alcançar ou manter a liderança resida justamente no padrão tecno-estético, que coincide em essência com a barreira estético-produtiva, que:

\footnotetext{
3 A denominação "padrão tecno-estético", como se esclarece em Bolaño (2000), foi adotada em homenagem a Dominique Leroy, que desenvolveu, em seus trabalhos fundadores sobre as artes do espetáculo, os conceitos de estrutura e de sistema tecno-estético. Embora o enfoque seja muito distinto, pois as definições de Leroy estão mais vinculadas a uma perspectiva estruturalista francesa, enquanto a de Bolaño deriva da micro heterodoxa, há também uma clara compatibilidade, sinalizando importantes possibilidades de diálogo entre a EPC brasileira e uma corrente fundadora, mas menos conhecida, da Economia da Comunicação e da Cultura francesa.
} 
[...] envolve os fatores que diferenciam o produto, como específicos padrões e modelos estéticos e de produção, cuja obtenção demanda esforços tecnológicos, de inovação estética, de recursos humanos e financeiros. Esses modelos acabam recebendo a adesão dos consumidores, desencadeando uma relação difícil mas possível - de ser rompida. Tal processo traduz-se no próprio bem, reunindo ainda técnicas de marketing e publicidade e criação de vinhetas ou embalagens, que servem para o reconhecimento do consumidor e estimular sua preferência. A criação e manutenção desta barreira requer investimentos em pesquisa, de modo que haja constante inovação dos produtos e evolução do modelo (BRITTOS, 2001, p. 84-85).

O conceito de padrão tecno-estético também vale para a TV fechada. Nesse caso, a lógica da oferta de pacotes de canais especializados faz com que ele apareça fragmentado, em distintos canais. Por exemplo, o padrão tecno-estético do Grupo Globo na TV paga encontra-se distribuído em diferentes canais com programação especializada ao longo das 24 horas do dia: esportes (Sportv e Canal Combate); filmes (Universal, Telecine e Canal Brasil); entretenimento (GNT e Multishow); arquivo de novelas e programas (Viva) etc. Assim, a fidelização que se busca é a um pacote de canais e não a uma grade única, como no caso da radiodifusão convencional.

Com isso, o planejamento da grade muda radicalmente, ganhando relevância a repetição dos programas em diferentes dias e horários para garantir a audiência no agregado frente a uma concorrência que adota uma estrutura de oferta semelhante. Em princípio, trata-se de oferecer o pacote mais diversificado e completo, visando atrair assinantes, com o que se introduziu no mercado televisivo a lógica da exclusão pelo preço, característica de outros mercados culturais. No entanto, desde o início, não se descarta a lógica da venda das audiências no mercado publicitário, que cresce ao longo do tempo, configurando um modelo de financiamento misto, ainda mais diversificado com a introdução de sistemas como o de pay per view.

Essa flexibilização de formatos e modelos de financiamento avança ainda com as alterações na concorrência em escala internacional, decorrentes da expansão da internet, com a digitalização geral da produção cultural e a sua incorporação ao sistema global das grandes plataformas de serviços. Nessas condições de mudança estrutural, as barreiras à entrada impostas pelas empresas líderes em nível nacional veem-se naturalmente fragilizadas frente ao grande capital internacional oligopolista, ainda que a experiência no setor ofereça ainda vantagens do ponto de vista estéticoprodutivo, dado o conhecimento internalizado pela empresa.

A esse respeito, Brittos enfatiza a questão da identidade, que ele se dedicava desde os seus estudos anteriores na perspectiva dos EC, vista agora como importante fonte de barreiras. Para que funcione seria necessário "haver um reconhecimento de superioridade por parte do público, a ponto de preferir seus produtos e alçar a empresa à condição de líder", com "definições que partem de como a companhia se reconhece, faz-se reconhecer e é reconhecida", o que "envolve opções sobre o que e como veicular e investimentos para melhor fazer e divulgar" (BRITTOS, 2001, p. 87).

Outro tipo de barreira, a político-institucional é ligada diretamente à regulamentação do mercado. Essa barreira se constitui especialmente quando se traduz "em posição que garanta ao agente econômico lugar privilegiado na disputa, dificultando a outros atores ingressarem ou crescerem no mercado" (BRITTOS, 2001, p. 90), independente de qual o poder que a define (Executivo, Legislativo ou Judiciário). 
Relaciona-se diretamente com estes organismos através da obtenção de posições diante de determinantes políticoinstitucionais, tendo em vista suas atribuições de edição de diplomas legais, decisões em processos e atos administrativos, poder de polícia e procedimentos em geral, incluindo ações de infraestrutura, regulação da concorrência, postura como poder concedente e opções frente a pesquisa e a tecnologia (BRITTOS, 2001, p. 89-90).

Na TV aberta, um exemplo de impacto direto é o sistema de concessões, cedidas e renovadas a partir do Estado, mas com restrições, casos do limite à participação do capital estrangeiro , 30\% desde 2002, e da proibição de distribuidoras da TV paga serem concessionárias da radiodifusão gratuita, a partir da Lei do Serviço de Acesso Condicionado (2011).

Há ainda limitação legal na TV paga para evitar propriedade cruzada, pois uma empresa com percentual societário em distribuidora não pode ser programadora. Assim, por exemplo, a compra da Time Warner pela AT\&T gerou a venda ou encerramento de atividades de canais da programadora na TV fechada que produziam conteúdo nacional, caso do canal esportivo Esporte Interativo, que surgiu como agente importante a partir da sua aquisição pela Time Warner (BOLAÑO; SANTOS, 2016), mas que encerrou suas atividades em 2018.

Como último exemplo, mas de interferência de decisão de agência reguladora, é a exigência pelo Conselho Administrativo de Defesa Econômica (CADE) de, na compra dos canais da Fox (News Corp) pela Disney, o Fox Sports tivesse que ser repassado para outra empresa que não fossem a ESPN (pertencente ao grupo internacional) ou o Sportv (Grupo Globo), de maneira a garantir maior disputa nesse segmento.

Após a defesa da tese, Brittos segue desenvolvendo sua perspectiva sobre as barreiras à entrada na produção televisiva. Num artigo particularmente importante, em que retoma a contribuição fundadora de Bain, além de Chesnay, Possas, Herscovici e outros, Brittos (2002) expõe e comenta a competente revisão de literatura feita por Schymura (1997) para, em seguida, retomar a sua própria classificação, separando as barreiras estético-produtivas das político-institucionais.

Trata, com isso, de situar a sua contribuição em relação à literatura microeconômica heterodoxa, inserindo-se na trajetória da EPC brasileira, contribuindo para a expansão de sua importante característica de incorporar, de forma criativa mas não eclética, ao referencial marxista de base a micro heterodoxa para a análise dos mercados culturais, num momento em que, reconhecendo a importância econômica dos meios de comunicação, boa parte dos autores do campo no Brasil procurava a solução fácil da economia ortodoxa.

Em 2010, Brittos retomou a questão do padrão tecno-estético como projeto coletivo de pesquisa, ao lado de seus orientandos na Unisinos. Tratava-se de sondar as possibilidades de ampliação do conceito, em diálogo com outras subáreas da comunicação. Assim, sob sua orientação, Kalikoske (2010) propôs uma classificação, dividindo os padrões em: hegemônico, anacrônico, emergente, periférico e alternativo.

O padrão alternativo dará origem, por sua vez, a uma classificação específica, considerando a existência na mídia alternativa de diferentes formas de gerência e construção de conteúdo, que definiram as seguintes categorias: não-hegemônico, público-estatal, institucional, popular e contra-hegemônico (BRITTOS; MENEZES, 2011). O objetivo era auxiliar os movimentos populares e sindicatos "a visualizarem o 
seu próprio processo de atuação política, em meio ao complexo universo da comunicação alternativa" (idem, p. 16).

Mesmo enfatizando o marco teórico geral relativo à análise microeconômica, é importante ainda apresentar o posicionamento do autor sobre a mercadoria nesse mercado. Mesmo sem ter tido tempo de participar do debate Fuchs-Bolaño, ${ }^{4}$ vê-se a posição de Brittos ao destacar, por um lado, a centralidade da mercadoria audiência produzida pela indústria televisiva, na definição de Bolaño (2000), na medida em que é com a venda da audiência que a radiodifusão se sustenta, impulsionando o conjunto do campo publicitário, inclusive na TV fechada. Por outro, rejeita explicitamente a ideia fuchsiana de trabalho da audiência:

\begin{abstract}
Objeta-se tal visão, já que a audiência não é o único produto, estando ao lado dos programas, disponibilizados em uma programação, a qual servem como eixo para captação do público. O trabalho de conquista da audiência - uma mercadoria rara, cuja quantidade e qualidade definirá seu preço -, não é do próprio receptor, que é parte do produto audiência e utiliza a programação em seus momentos de lazer, mas dos trabalhadores culturais, inserindo-se aí a produção de cultura no capitalismo (BRITTOS, 2001, p. 72-73).
\end{abstract}

Com o falecimento prematuro de Brittos, a linha de pesquisa sobre o padrão tecnoestético não pôde seguir como objetivo de primeiro plano, o que não significa que o desenvolvimento dos conceitos de barreiras à entrada e de padrões tecno-estéticos na linha inaugurada pelos trabalhos de Brittos e Bolaño tenha cessado. Uma busca por esses termos nas bases de dados das principais revistas da área de Comunicação do Brasil mostrará a atual situação de uso e desenvolvimento desses conceitos.

\title{
FASE DA MULTIPLICIDADE DA OFERTA
}

O século XXI mostra momentos de disputa acirrada no mercado comunicacional, decorrente da mudança estrutural do capitalismo que, no campo da comunicação e da cultura, levou a níveis extremamente elevados de concentração e centralização do capital, deslocando a disputa pelos diferentes setores do audiovisual para o plano internacional, o que fragiliza tanto as barreiras à entrada de atores hegemônicos no plano nacional como a própria capacidade reguladora dos estados nacionais frente ao oligopólio global em que se organiza a produção simbólica.

Brittos concebeu a delimitação conceitual de "fase da multiplicidade da oferta" para esse período histórico, em que:

[...] o momento de maior enfrentamento dos participantes do mercado abriu-se em 1995, quando duas indústrias, de televisão aberta e por assinatura, passaram a concorrer definidas. É a Fase da Multiplicidade da Oferta da TV do Brasil, que permanece até

\footnotetext{
${ }^{4}$ O debate gira em torno da ideia de "trabalho da audiência", que Fuchs herda de Dallas Smythe, adaptando-a ao contexto das plataformas digitais. Bolaño, que já havia formulado uma crítica a Smythe em sua tese de 1993 (BOLAÑO, 2000), questiona Fuchs em artigo publicado na revista Television and New Media (BOLAÑO; VIEIRA, 2014), que publica, no mesmo número, uma resposta deste. Bolaño replica na TripleC (BOLAÑO, 2015), que também publica, no mesmo número, uma resposta de Fuchs. Rodrigo Moreno Marques (2018), por sua parte, também se refere ao debate, na apresentação de sua própria abordagem a respeito da problemática da relação entre trabalho, valor, informação e conhecimento.
} 
hoje e é caracterizada pelo aumento do número de canais, provocando uma maior disputa entre as emissoras, decorrendo daí a popularização das programações (BRITTOS, 2001, p. 277).

Note-se que o ano de 1995, tomado como ponto de corte na história da TV brasileira, é justamente o da constituição de uma regulamentação para o setor, que colocava barreiras de mercado específicas com a promulgação da Lei do Cabo. É claro que o processo remonta ao final dos anos 1980, com as disputas sobre o modelo de TV paga que viria a ser implantado no Brasil, mas só em 1993 que Globo e Abril, os dois maiores capitais do campo cultural do país naquele momento, entram no mercado, acabando por constituir uma estrutura duopólica, que sofre posteriormente uma desconcentração, mantendo-se, em todo caso, como um oligopólio altamente concentrado.

As transformações estruturais que atingiam o audiovisual já estavam maduras e o mercado de TV paga já se mostrava suficientemente atraente. Brittos (2009, p. 22) define que:

\begin{abstract}
É um período marcado pela introdução de um conjunto de mudanças tecnológicas [...]. Também é o momento assinalado pelo ingresso de outros agentes econômicos, muitos oriundos de áreas extra-comunicacionais (capitais de ramos industriais e financeiros), que passam a investir em mídia, não raro em busca de resultados rápidos, nem sempre concretizados. A nova orientação da regulamentação, voltada à facilitação dos agentes de mercado (mas não só isso) surge como uma demanda das indústrias, que, no caso da cultura, têm um poder de pressão superior.
\end{abstract}

Além disso, o aumento do número de canais também se dá a partir do ingresso de canais UHF e a constituição de novas redes, caso da MTV, associação do Grupo Abril com a MTV Networks International (parceria Viacom, Paramount Pictures e CBS). Também canais religiosos começam a fazer-se presentes utilizando essa faixa de frequência, além da entrada de novos concorrentes de tipo tradicional na TV aberta brasileira, configurando um ambiente "com seis principais redes comerciais abertas, além de outras de menor dimensão" (BRITTOS, 2001, p. 283). Tudo somado, a indústria audiovisual nacional mostrava-se muito mais diversificada que nos anos anteriores, de exclusividade do oligopólio da TV de massa construído ao longo dos anos 1970, com enorme hegemonia da Rede Globo.

A reconfiguração do setor gerou pequenos sustos à liderança da Globo em distintos momentos, geralmente frente a novos padrões tecno-estéticos de suas concorrentes. Em todo caso, a Globo mantém até hoje a liderança de mercado, ainda que a audiência se reduza a cada ano, não necessariamente em favor de seus concorrentes diretos, pois, para além dos canais abertos e pagos, a concorrência que marca a nova fase ultrapassa o próprio setor, incorporando a disputa com outras mídias.

A multiplicidade de oferta de produtos e serviços ganhou evidência dentro desse quadro conjuntural, numa onda de otimismo das mídias, depois frustrada. Com a ampliação da concorrência no mercado de bens simbólicos, ao qual foram agregados novos produtos televisivos, sem um crescimento equivalente do público consumidor, ocorreu uma mudança na audiência. A televisão cresceu, ampliou seu número de agentes, ficou mais complexa, ofereceu mais opções aos consumidores e, como resposta, houve uma descentralização de focos. Em outras palavras, a TV ganhou concorrentes à altura e, mesmo não perdendo seu posto de meio 
hegemônico, acabou se fragilizando com a ampliação dos competidores (BRITTOS, SIMÕES, 2011, p. 22).

Brittos (2009) resume assim as características da nova fase: passagem de uma lógica da oferta a uma lógica da demanda, na medida em que os espectadores começam a confeccionar a dieta audiovisual e, em consequência, a debilitar a atividade estratégica da programação por parte dos radiodifusores; tendência ao pagamento pelo consumo e à entrada de capitais no setor audiovisual, assim como um incremento importante do gasto audiovisual per capita; transição de um modelo de fluxo a um modelo editorial, de um modelo de comunicação ponto-massa a uma comunicação ponto-ponto; incremento notável da flexibilidade no consumo, pela personalização, que leva à confecção dos menus individuais; e maior interatividade homem-máquina.

A partir deste breve resumo, duas questões relevantes para o campo da EPC se apresentam. Primeiro, a definição da fase da multiplicidade da oferta nos trabalhos de Brittos, particularmente na tese de 2001, tomam como referência a conhecida periodização da TV brasileira de Mattos (2010), a qual não se baseia nos elementos da microeconomia heterodoxa adotada na construção do seu marco teórico, esboçados no item anterior. Não obstante, a definição presente na primeira citação apresentada neste item é perfeitamente compatível com a posição adotada por Bolaño (2004), na sua incorporação do conceito na segunda edição de Mercado brasileiro de televisão.

Para este, o ano de 1995 deve ser tomado como ponto de corte porque representa o momento de inflexão do mercado de TV segmentada, da fase concorrencial inicial para a forma de oligopólio, com um período de transição entre 93 e 95, como esclarece justamente Brittos na sua tese, repetindo de alguma forma o movimento, estudado anteriormente por Bolaño, de passagem, na TV de massa, do mercado concorrencial dos anos 1950 e 60 ao oligopólio dos 70, quando se constitui e expande o sistema de broadcasting no país. A transição, neste caso, ocorre entre a entrada da Globo, o pivô da mudança, em 1965, e setembro de 1969, quando a transmissão do Jornal Nacional simultaneamente para São Paulo, Rio de Janeiro e Belo Horizonte inaugura a primeira rede nacional.

No caso da TV segmentada, o processo é muito mais rápido e a sua conclusão, em 1995, inaugura uma nova fase não apenas neste mercado, mas no conjunto do audiovisual, na medida em que se traduz na coexistência de duas trajetórias tecnológicas, no sentido neoshumpeteriano do termo. A fase da multiplicidade da oferta para Bolaño (2004) é aquela em que essas duas trajetórias tecnológicas (TV de massa e TV segmentada) convivem, ambas sob a forma de oligopólio, disputando a audiência entre si. Mas não se trata de nada distinto da definição do próprio Brittos que vimos aqui.

Há, por certo, aí uma tendência à unificação das duas trajetórias, mas esta não se dará sobre a base de nenhuma delas, ambas serão lançadas no movimento mais abrangente da economia política da internet e das plataformas digitais que ocorre em nível global, fruto da reestruturação capitalista. Esse é precisamente o movimento que estamos presenciando e que sinaliza a segunda questão: a de superação da fase da multiplicidade da oferta, que passaria, em algum momento, a ser entendida como transição entre a velha Indústria Cultural centrada na TV de massa, do século XX, e a nova estrutura de mediação, do século XXI, cujos contornos tornam-se cada vez mais claros. Para ser coerente com o método dialético da pesquisa em EPC, essa é a hipótese de trabalho que nos deve nortear agora nos estudos históricos sobre a TV brasileira. 


\section{A IDEIA DE PLURITV}

Brittos (2011, p. 286) já sinalizara que "o fornecimento de TV pela Internet é uma tendência crescente, pelo que possibilita de interatividade", o que só se tornaria realidade com a expansão da banda larga e sob o comando dos grandes agentes internacionais, como Youtube/Google, Netflix e Facebook. No interior dos grupos Cepos e OBSCOM, pouco antes do seu falecimento, a divisão de tarefas colocava este último na linha de frente do estudo da economia política da internet, enquanto o Cepos centrava-se na televisão e no fenômeno da disseminação das telas.

O barateamento dos equipamentos digitais e a redução consequente dos custos de produção permitiam um crescimento exponencial das ofertas de todo tipo de conteúdo audiovisual, inclusive amadores, sem relação imediata com as indústrias culturais até então conhecidas, num movimento de ampliação da concorrência, pelo lado dos produtores, e de aprofundamento da concentração do poder midiático em torno de plataformas em número cada vez mais reduzido em nível mundial, englobando as mais diversas possibilidades de acesso, intercâmbio, fruição, compra e venda de produtos digitalizáveis. Assim, produção, distribuição e consumo de bens simbólicos foram transformados, afetando o conjunto das indústrias culturais e da comunicação.

Brittos escreveu dois livros sobre o projeto de TV digital brasileiro, um pioneiro, em parceria com Bolaño (BRITTOS; BOLAÑO, 2007), e outro posterior, com Simões, para a Intercom, em que afirma que a televisão passaria a "evidenciar principalmente o seu conteúdo e multiplicar as formas de estruturar suas bases de recepção, com a possibilidade de anexar-se a outros produtos físicos e simbólicos" (BRITTOS, SIMÕES, 2011, p. 19) e avança a ideia de "PluriTV", que marcaria este novo momento histórico da principal mídia brasileira. O conceito, que começava então a esboçar-se:

Sintetiza a ideia de pluralidade de formas na cadeia de valores da televisão, considerando a digitalização e transitando tanto pelos aspectos técnicos quanto pelos simbólicos. Abarca essa nova diversidade no fazer e consumir a mídia TV, provinda dessas mudanças de paradigmas, ocorridas principalmente a partir da primeira década do século XXI. A PluriTV surge a partir de cruzamentos de meios e de inovações, no que tange ao audiovisual televisivo, em que a questão da convergência tecnológica aparece em destaque (BRITTOS; SIMÕES, 2011 p. 64).

A lógica de fundo da PluriTV segue sendo aquela da fase da multiplicidade da oferta. A TV aberta ganhou concorrentes de diversos tamanhos. Desta forma, "[... ] mais do que aumentar a quantidade de monitores que captam sinal de TV, ocorre uma reorganização dos modelos do que será transmitido e como será encaminhado ao espectador, gerando gradativo crescimento das opções de fruição do audiovisual" (BRITTOS, SIMÕES, 2011, p. 65-65).

A ideia de PluriTV, tal como formulada no livro e esboçada aqui e ali nos trabalhos de alguns dos seus orientandos, poderia ser útil na organização da pesquisa - valendo-se das categorias tradicionais da EPC, inclusive aquelas desenvolvidas por Brittos - dos diferentes setores do audiovisual, cada vez mais diversificados, facilitando uma visão de conjunto. O estudo do sistema brasileiro de TV digital foi também uma contribuição importante na formulação de alternativas de democratização do setor, mas o certo é que a expansão das plataformas digitais na década que se seguiu aponta para uma mudança estrutural muito mais radical e destrutiva que aquela imaginada pelos participantes do debate em torno da implantação da TV digital. 
A interatividade passou a ocorrer mais devido ao desenvolvimento da chamada SmartTV, a TV conectada, de acordo com as necessidades da publicidade e da indústria em geral, que pelo aplicativo de interação da TV Digital. Em troca, o uso das mídias sociais para conversação entre quem produz determinada informação e quem a consome, acaba gerando nova lacuna quando pensado este uso para serviços públicos, como marcação de consultas ou o acesso a informações sobre processos ligados à previdência social. $O$ impacto social perdeu-se em meio às escolhas econômicas.

\begin{abstract}
A PluriTV instabilizou uma tradição de ver televisão, trazendo opções paralelas à programação que era rotineiramente transmitida. A oferta de produtos por demanda, por exemplo, deu ferramentas para que um grupo de telespectadores migrasse de grade de programação para o download de dados, assistindo aos conteúdos no momento escolhido, mesmo que esse serviço implique custos (BRITTOS, SIMÕES, 2011, p. 67).
\end{abstract}

A TV está presente em distintos lugares, multiplicando seus formatos e telas para adequar-se às mídias móveis, locativas e em transportes como aviões e metrôs. Todo esse conjunto de possibilidades confirma o que Brittos e Simões (2011) apontam como a saída da condição de "rainha do lar" para espraiar-se por outros momentos do nosso cotidiano, exigindo novas formas de produção, distribuição e consumo dos bens culturais. Assim:

\begin{abstract}
Sob esse foco, a expansão da televisão gera efeitos colaterais em todos os envolvidos, forçando mudanças de postura de múltiplos lados. $O$ espectador passa a ter uma nova relação com o conteúdo audiovisual e gradativamente perde o encantamento que antes tinha, assim como a fidelidade ao meio, compartilhando com outras mídias o tempo que antes era exclusivo para ver um programa de auditório, telejornal ou teledramaturgia. Os patrocinadores acabam por pulverizar seus investimentos, já que percebem que as audiências também estão distribuídas de forma mais ampla, e passam a focar segmentos-alvo e menos massificados. As emissoras, que se posicionam no Brasil como produtoras, além de programadoras, deslocam investimentos para outros acessos ao público, diversificando seus conteúdos e meios (destacando aqui a internet) e tentando manter a liderança na captura da maior fatia do bolo publicitário. O Estado passa a tentar regular essa nova estrutura mutante, todavia, é lento diante da velocidade das alterações e a pressão dos agentes econômicos, que criam fatos precedentes, adiantando-se ao mercado (BRITTOS; SIMÕES, 2011, p. 66-67).
\end{abstract}

Nota-se aqui o sentido da formulação do conceito de PluriTV e a sua relevância para o entendimento da realidade atual das indústrias culturais. No entanto, é preciso reconhecer os seus limites para a caracterização do problema de fundo, da transição da velha Indústria Cultural do século $X X$ ao novo sistema de mediação global centrado nas plataformas digitais. É certo que o movimento atual vai no sentido de disseminar as telas por todos os lugares, mas a questão é: o que será do nosso sistema global de cultura uma vez superada a fase da multiplicidade da oferta? 


\section{CONSIDERAÇÕES FINAIS}

Como apresentado ao longo deste artigo, até pelas especificidades do materialismo histórico-dialético que a EPC brasileira toma para estudar a Indústria Cultural, a obra de Valério Brittos acompanha a evolução tecnológica dos setores convergentes da informação, da comunicação e da cultura, em ligação direta com a análise das mudanças históricas do capitalismo, mas o foco da atenção não são as forças produtivas, senão as relações de produção, tomando aquelas como pressuposto.

As categorias aqui revistas, formuladas ou desenvolvidas pelo autor no interior de uma tradição de pesquisas relativamente jovem, como é a da EPC brasileira, apontam caminhos que vêm sendo trilhados e que se apresentam como promissores para a compreensão do que ocorre hoje com o sistema global de cultura.

Toda a discussão de Brittos sobre as barreiras à entrada e os padrões tecno-estéticos, especialmente a formulação da ideia de padrão tecno-estético alternativo, devem ser tomadas como elementos importantes para a compreensão das relações sociais constituídas no âmbito da cultura, eivadas de contradições.

A fase da multiplicidade da oferta não é outra coisa senão um momento particular de estruturação das formas de controle social e de construção da hegemonia que, num determinado recorte, podem ser entendidas sob o conceito de PluriTV, que não passa de uma forma interessante de organizar o pensamento para entender determinada parte dessa realidade histórica.

No conjunto, esperamos ter deixado claro que se trata de um aporte amplo, complexo e bem apoiado num paradigma teórico tão relevante como o da crítica da economia política. Neste texto, apenas algumas categorias foram consideradas, que indicam a importância da EPC brasileira para a compreensão da organização dos mercados culturais, incorporando os avanços da micro heterodoxa ao enfoque marxista de base, de forma crítica e sem ecletismo. Mais importante, tratamos de deixar assentada a existência dessa tradição, através do estudo de parte da obra de um de seus formuladores, visando explicitar ainda alguns dos caminhos que se pode avançar nesta empreitada.

Assim, na primeira parte, concluímos com o programa de pesquisa inacabado de Brittos sobre as barreiras à entrada e os padrões tecno-estéticos; na segunda, lançamos o desafio de formular as condições históricas de superação dialética da fase da multiplicidade da oferta; e, na terceira, explicitamos o interesse mas também o caráter limitado do conceito de Pluri-TV para a compreensão da atual transição do sistema global de cultura, da velha Indústria Cultural do século XX para a nova estrutura de mediação constituída pelas plataformas digitais. Três caminhos, portanto, a serem trilhados pelos pesquisadores identificados com o paradigma da EPC brasileira. Fica o desafio.

Artigo recebido em 28/01/2020 e aprovado em 16/04/2020.

\section{REFERÊNCIAS}

BOLAÑO, C. Mercado brasileiro de televisão. 2.ed. São Paulo: EDUC, 2004.

BOLAÑO, C. Indústria cultural, informação e capitalismo. São Paulo: Hucitec/Polis, 2000. 
BOLAÑO, C. Digitalisation and Labour: A Rejoinder to Christian Fuchs. TripleC, Londres, v. 13, n. 1, p. 79-83, 2015.

BOLAÑO, C.; BRITTOS, V. A TV brasileira na era digital. São Paulo: Paulus, 2007.

BOLAÑO, C.; VIEIRA, E. The Political Economy of the Internet: Social Networking Sites and a Reply to Fuchs. Television and New Media, v. 16, n. 1, p. 52-61, 2 abr. 2014.

BRASIL, Lei n. 12.485, de 12 de setembro de 2011. Dispõe sobre a comunicação audiovisual de acesso condicionado; altera a Medida Provisória n 2.228-1, de 6 de setembro de 2001, e as Leis n 11.437, de 28 de dezembro de 2006, 5.070, de 7 de julho de 1966, 8.977, de 6 de janeiro de 1995, e 9.472, de 16 de julho de 1997; e dá outras providências. Disponível em: <http://www.planalto.gov.br/ccivil_03/_Ato20112014/2011/Lei/L12485.htm>. Acesso em: 23 jan. 2020.

BRITTOS, V. C. Capitalismo contemporâneo, mercado brasileiro de televisão por assinatura e expansão transnacional. 2001. 425f. Tese (Doutorado) - Programa de Pós-Graduação em Comunicação e Culturas Contemporâneas, Universidade Federal da Bahia-UFBA, Salvador, BA, 2001.

BRITTOS, V. Indústrias culturais e oligopolização: as barreiras da televisão. In: ENCUENTRO DE ECONOMÍA POLÍTICA DE LA COMUNICACIÓN DEL MERCOSUR, 2., 2002, Brasília. Anais.... Aracaju: OBSCOM-UFS 2002.

BRITTOS, V. C. As barreiras à entrada dos processos televisivos. Diálogos Possíveis, v. 4. n. 1, p. 175-188, 2005.

BRITTOS, V. C. Digitalização, democracia e diversidade na fase da multiplicidade da oferta. In: _ (Org.). Digitalização, diversidade e cidadania: convergências Brasil e Moçambique. São Paulo: Annablume, 2009. p. 17-30.

BOLAÑO, C. R. S.; BRITTOS, V. C. Rede Globo: 40 anos de poder e hegemonia. São Paulo: Paulus, 2005.

BRITTOS, V. C.; MENEZES, E. S. Do vídeo popular às especificidades do padrão tecnoestético alternativo. Revista Eptic, São Cristóvão, v. 13, n. 3, p. 1-17, set.-dez. 2011.

BRITTOS, V. C.; SIMÕES, D. G. Para entender a TV Digital: tecnologia, economia e sociedade no século XXI. São Paulo: Intercom, 2011.

KALIKOSKE, A. Padrões tecno-estéticos e hegemonia televisiva no Brasil. In: CONGRESSO DE CIÊNCIAS DA COMUNICAÇÃO NA REGIÃO SUL, 11., 2010, Novo Hamburgo. Anais do XI Congresso de Ciências da Comunicação na Região Sul. São Paulo: Intercom, 2010. Disponível em: <http://www.intercom.org.br/papers/regionais/sul2010/resumos/R20-1313-1.pdf>.

Acesso em: 28 jan. 2020.

LOPES, R. S.; SANTOS, A. D. G. dos; MOTA, J. S. Revista Eptic Online: produção em EPC e interdisciplinaridade no campo comunicacional (2009-2014). Liinc em Revista, Rio de Janeiro, v. 11, n. 2, p. 475-490, nov. 2015.

POSSAS, M. L. Estruturas de mercado em oligopólio. 2.ed. São Paulo: Hucitec, 1987.

MARQUES, R. M. Trabalho e valor nas mídias sociais: uma análise sob as lentes do marxismo. Trabalho e Educação, Belo Horizonte, v. 27, n. 3, p. 111-130, set./dez. 2018.

MATTOS, S. História da televisão brasileira: Uma visão econômica social e política. 5.ed. Petrópolis: Vozes, 2010. 
SANTOS, A. D. G. dos; BOLAÑO, C. R. S. Las estrategias de mercado de Esporte Interativo: regionalización y capital extranjero en la televisión brasileña. Chasqui Revista Latinoamericana de Comunicación, Quito, n. 133, p. 283-296, dez. 2016.

SCHYMURA, L. G. Barreiras à entrada: o caso do setor de creme dental brasileiro. Revista Brasileira de Economia, Rio de Janeiro, v. 51, n. 4, p. 551-566, out.-dez. 1997. 